\title{
On the applicability of micro-injection moulding simulations to multivariate integrated process/product optimization
}

Baruffi, F.; Calaon, M.; Tosello, G.; Elsborg, R.

Published in:

Proceedings of WCMNM 2018

Publication date:

2018

Document Version

Publisher's PDF, also known as Version of record

Link back to DTU Orbit

Citation (APA):

Baruffi, F., Calaon, M., Tosello, G., \& Elsborg, R. (2018). On the applicability of micro-injection moulding simulations to multivariate integrated process/product optimization. In J. Valentini, M. Byung-Guk Jun, K. Dohda, \& S. Dimov (Eds.), Proceedings of WCMNM 2018

\section{General rights}

Copyright and moral rights for the publications made accessible in the public portal are retained by the authors and/or other copyright owners and it is a condition of accessing publications that users recognise and abide by the legal requirements associated with these rights.

- Users may download and print one copy of any publication from the public portal for the purpose of private study or research.

- You may not further distribute the material or use it for any profit-making activity or commercial gain

- You may freely distribute the URL identifying the publication in the public portal 


\title{
On the applicability of micro-injection moulding simulations to multivariate integrated process/product optimization
}

\author{
F. Baruffi', M. Calaon 1 , G. Tosello', R. Elsborg ${ }^{2}$ \\ ${ }^{1}$ Technical University of Denmark, Department of Mechanical Engineering, \\ Produktionstorvet, Building 427A, 2800 Kgs. Lyngby, Denmark \\ ${ }^{2}$ Ortofon A/S, Nakskov, Denmark
}

\begin{abstract}
As in conventional injection moulding, process simulation of micro-injection moulding $(\mu \mathrm{IM})$ is a powerful tool for the optimization of the design of mould, parts and process. However, the miniaturized scale of the micro products introduces relevant challenges in terms of both validation and accuracy of the simulation results. In the present work, a case study based on the $\mu \mathrm{IM}$ process of thermoplastic elastomer (TPE) micro rings for sensors application is treated. Moulding process simulations using Autodesk Moldflow Insight $2016 \circledast$ were applied with the aim of predicting the effects of the variation of mould temperature, melt temperature, injection speed and holding pressure on the part geometry. The outcomes of the simulations were directly compared to real parts based on high accuracy optical measurements. The numerical model was calibrated by fitting simulations results to experimental observations taking into account the measurement uncertainty. The calibrated model was validated against the effects of the process parameters and then used to carry out a virtual optimization. The results showed that simulations correctly predicted the effects of the four investigated process parameters on the part geometrical accuracy, opening the door to profitable $\mu \mathrm{IM}$ virtual experiments.
\end{abstract}

Keywords: Process simulations, Micro-injection moulding, TPE

\section{Introduction}

In recent days, the demand of miniaturized, complex-shaped components has increased in many engineering fields such as biotechnology, avionics, communication, automotive, medicine, etc. The need of meeting this fast growth led to the development of new manufacturing processes [1]. Micro-injection moulding $(\mu \mathrm{IM})$ is one of them: it is a technology that effectively enables the manufacturing of micro plastic components in the large volumes typical of replicationbased processes [2]. As for conventional injection moulding (IM), process simulations are a powerful tool for $\mu \mathrm{IM}$ also. They can be used to shorten micro products time-to-market by avoiding or reducing development and re-engineering time [3], leading to a consistent overall cost reduction.

Different commercial software packages such as Autodesk Moldflow ${ }^{\circledR}$, Sigmasoft $₫$ and Moldex $3 D \circledR$ are available on the market to simulate injection moulding processes. However, such software tools are specifically made for IM. When dealing with $\mu \mathrm{IM}$, such software packages can still be applied, but the results usually lack of the needed quantitative accuracy [4]. This happens because the polymer flow inside microcavities is characterized by peculiar phenomena that are not modelled inside commercial software tools. Firstly, when flowing inside a micro channel (i.e. a channel whose section has the main dimension in the micrometric range), polymers have a strong tendency to slip [5], invalidating the no-slip conditions that is assumed in IM models. Secondly, the rheological data at high shear rates, which are typical of $\mu \mathrm{IM}$ [6], are usually not measurable by means of common testing equipment such as shear or capillary rheometers [7]. This lack of information, which is caused by the extreme difficulty of measuring viscosity of a polymer melt flowing inside micro cavities, can seriously affect the simulation results. Other approximations made by commercial software that do not usually apply to $\mu \mathrm{IM}$ are constant heat transfer coefficient [8], absence of the elongation component of viscosity and of surface tension [9]. Another complication is related to the validation phase. In fact, pressure and temperature sensors cannot be easily placed inside micro cavities, and thus monitored and simulated data are not usually comparable. Short-shots are also difficult to carry out when very small injection volumes are involved, preventing from performing a validation based on the filling pattern.

However, a proper modelling strategy can help to achieve results that are more precise. Marhöfer et al. [10] used a multi-scale mesh for modelling $\mu \mathrm{IM}$ of a microfluidic device using Autodesk Moldflow 2013®. By including mould blocks and barrel in the model, the authors showed how simulations results were largely improved. Costa et al. [11] studied the best strategies for carrying out a precise simulation of injection moulding of a flat thin cavity and of a miniaturized dogbone shaped part using Autodesk Moldflow 2010®. Their results showed that the modelling strategy for the nozzle tip strongly influenced the accuracy of the simulation. Marhöfer et al. [12] successfully used process simulations in the gate design of two microfluidic components. The validation phase was based on SEM images of short shots that were compared with the correspondent filling steps.

At present, the analysed literature still lacks of an investigation on the possible usage of $\mu \mathrm{IM}$ simulations to predict the dimensional quality of a moulded micro polymer part. The present work aims at applying process simulations as a virtual process/product optimization tool for thermoplastic elastomer (TPE) micro rings manufactured by $\mu \mathrm{IM}$. To calibrate the numerical model, a functional geometry of the part was chosen as term of comparison between simulation results and real measurements. The effects of four different process parameters were then studied. The validated numerical model was finally used in a virtual

World Congress on Micro and Nano Manufacturing

Edited by Joško Valentinčič, Martin Byung-Guk Jun, Kuniaki Dohda, and Stefan Dimov

Copyright (c) 2018 WCMNM 2018 Organisers :: Published by Research Publishing Singapore

ISBN: 978-981-11-2728-1 :: doi:10.3850/978-981-11-2728-1_18 
optimization phase, aiming at meeting the target for the selected geometry.

\section{Materials and methods}

\subsection{Experimental details}

The micro component object of the study was a thermoplastic elastomer (TPE) micro ring used in sensor applications. Fig. 1 shows the main geometrical characteristics of the part.

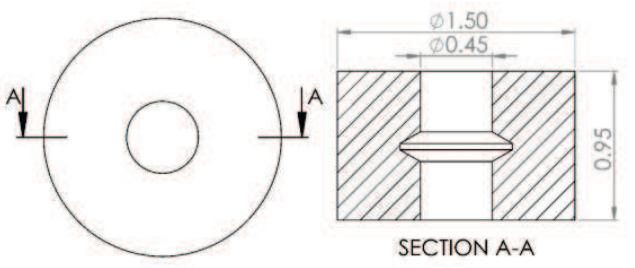

Fig. 1. Geometry and nominal dimensions in $\mathrm{mm}$ of the moulded micro ring.

The outer diameter (OD) was selected as output for the validation of simulations results based on experimental observations, being it a geometry that has a decisive impact on the component functionality. The material used was a styrene-ethylene-butylenestyrene (SEBS) that combined the desired elasticity with low viscosity, thus easing the flow inside microsized channels. Injection moulding experiments were carried out with a Wittmann-Battenfeld MicroPower 15 $\mu \mathrm{IM}$ machine having a $14 \mathrm{~mm}$ plasticization screw and a separate $5 \mathrm{~mm}$ injection plunger. A replaceable insert with four cavities was used as master for replication. Structured micro pins co-axial with the cylindrical cavities generated the central hole of the rings.

A Design of Experiment (DoE) approach was used to evaluate the effects of the process on OD. Four parameters were varied: holding pressure, melt temperature, mould temperature and injection speed. These variables were selected since they are widely recognized as the ones having the biggest influence on the moulding outcome [2]. A general full factorial design of experiment with five replicates was performed. Mould and melt temperatures were varied on two levels, while holding pressure and injection speed on three, resulting in 36 different process combinations. The parts moulded during the first ten cycles of each process combination were discarded. Table 1 shows the details of the experimental design.

Table 1. Experimental settings

\begin{tabular}{ll}
\hline Process parameter & Levels \\
\hline Holding pressure $p_{\text {hold }} / \mathrm{bar}$ & $300,500,700$ \\
Melt temperature $T_{\text {melt }}{ }^{\circ} \mathrm{C}$ & 210,225 \\
Mould temperature $T_{\text {mould }} /{ }^{\circ} \mathrm{C}$ & 30,40 \\
Injection speed $v_{\text {inj }} /(\mathrm{mm} / \mathrm{s})$ & $50,70,90$ \\
\hline
\end{tabular}

The diameters of the moulded micro rings were measured with a focus variation optical instrument (Alicona InfiniteFocus) featuring a $1.75 \mu \mathrm{m}$ digital lateral resolution. A preliminary uncertainty assessment procedure based on ISO 15530-3 [13] allowed the calculation of the expanded uncertainty $U$, which was equal to $2.0 \mu \mathrm{m}$ by considering a $95 \%$ confidence interval.

\subsection{Simulation setup and model calibration procedure}

The commercially available software Autodesk Simulation Moldflow Insight (ASMI) 2016® was used for the numerical analysis. The simulation model comprised the four parts and the feed system. A 3D meshing was applied to such geometry. The commonly used 2.5 D Hele-Shaw approximation is in fact not suitable for $\mu \mathrm{IM}$ simulations since the hypothesis of constant pressure along the thickness of the micro geometries cannot be made when flow in micro channels is to be simulated [11,12]. To reduce the computational effort but, at the same time, achieve accurate results, a multi-scale mesh was used. Element sizes ranging from $500 \mu \mathrm{m}$ to $50 \mu \mathrm{m}$ were set (see Fig. 2). To increase the accuracy of the results, the region of interest (i.e. ring geometry and the gate) was more finely discretized than the sprue, where the polymer flow followed a relatively simple pattern. The model contained $1.4 \times 10^{6}$ tetrahedrons.

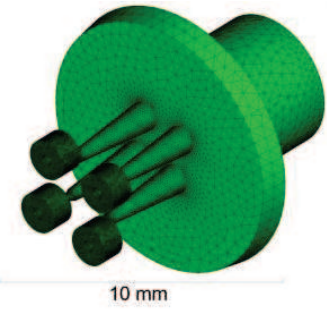

(a)

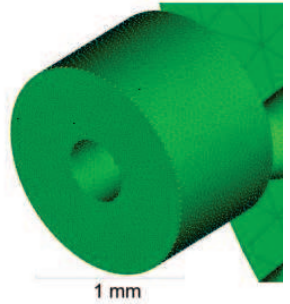

(b)
Fig. 2. (a) Meshed model and (b) detail of the meshed micro ring.

In ASMI, the flow was modelled by Navier-Stokes equations in 3D. As regard the material data, CrossWLF and Tait models were used to describe the rheological and thermodynamic behaviour of the plastic respectively. Material data provided by the material supplier were used to fit the two models and then imported in ASMI. A "Fill+Pack+Warp" analysis sequence was run in order to obtain the final dimensions of the parts after the end of the moulding cycle. As boundary conditions, the process settings employed in the actual experiments were selected to reproduce the real process conditions. After the analyses were completed, the spatial coordinates of the nodes standing on the outer diameter of the meshed rings were extracted and a circle was mathematically fitted to calculate the OD value. For each process condition, the four ODs corresponding to the four cavities were averaged in order to eliminate any deviation introduced by non-perfect mesh symmetry.

The mould dimensions correspondent to the part OD were measured with an optical coordinate measuring machine having $0.5 \mu \mathrm{m}$ lateral resolution. The result of such measurement was initially assigned to the CAD model that was then meshed in ASMI. Particularly, the outer diameter of the cavity ODmould was equal, on average, to $1.55 \mathrm{~mm}$. By assigning such a dimension to the model, the numerical results overestimated the experimental observations. Therefore, a calibration procedure aiming at optimizing the model dimension 
ODmodel with respect to the measured $O D$ of the moulded parts was carried out. Fig. 3 shows the flowchart of the calibration procedure: $\mathrm{OD}_{\text {model }}$ was progressively decremented by a $5 \mu \mathrm{m}$ step until the numerical results fitted the experimental observations. Therefore, 36 process simulations corresponding the 36 DoE combinations were run for each of the calibration steps. The calibration procedure was ended when the average of results of the numerical model for all DoE combinations ODnum fell inside the uncertainty interval built around the average of the experimental results $\mathrm{OD}_{\text {exp. }}$.

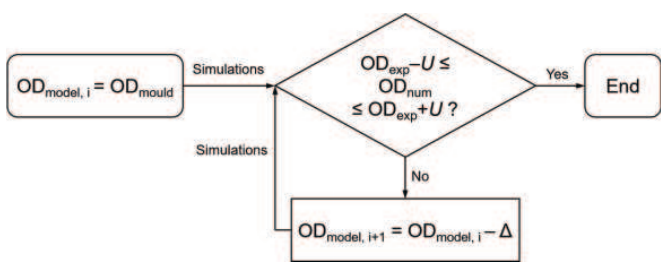

Fig. 3. Flowchart of the model calibration procedure. $\Delta$ was equal to $5 \mu \mathrm{m}$.

\section{Results and discussion}

\subsection{Model validation}

Fig. 4 shows the results of model calibration. Starting from a value of $\mathrm{OD}_{\text {model }}$ equal to the real mould dimension, six steps, correspondent to a reduction of $30 \mu \mathrm{m}$, were necessary to fit the experimental data according to the selected procedure. In particular, a final dimension of $1.520 \mathrm{~mm}$ was chosen for the model. The trend of ODnum against $O D_{\text {model }}$ was very close to linear: the amount of shrinkage of the part was linear with respect to the mould dimension. Moreover, the fact that, when using a model having the same size as the real mould cavity, simulation results overestimated the real part dimensions demonstrates that the real polymer melt underwent a larger amount of shrinkage than predicted by the $p v T$ model.

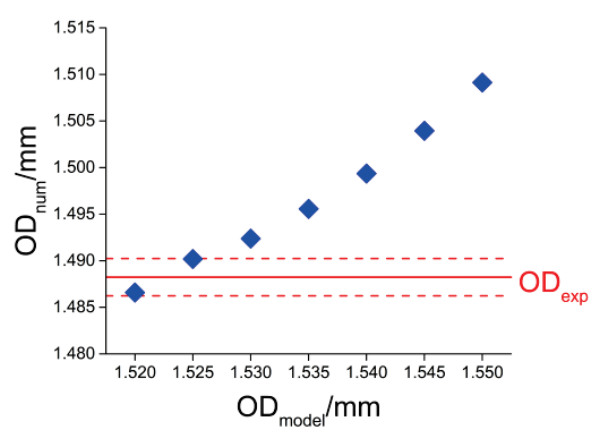

Fig. 4. $O D_{\text {num }}$ as function of $O D_{\text {model }} . O D_{\text {exp }}$ is indicated by a red line. The red dashed lines indicate the interval identified by the expanded uncertainty $U$.

The calibrated model was then used to validate the simulations with respect to the effects of the four process parameters (see Table 1) on the outer diameter of the produced micro rings. Fig. 5 shows the comparison of moulding experiments and simulations in terms of main effects plots.

Firstly, it is worth observing that $O D$ averages were always lower than the design target of $1.5 \mathrm{~mm}$ (see
Fig. 1), meaning that the level of shrinkage has to be reduced to meet the specifications. The average deviation between experiments and simulation results was $1.6 \mu \mathrm{m}$. This value was completely covered by the uncertainty $U$, and therefore the simulations were generally able to accurately predict the outer diameter of the micro moulded rings. As regard the effects of the process parameters on OD, a good agreement was also observed. The use of the high level of mould temperature provided an increase of $O D$ for both simulations and real parts. This happened because, by increasing $T_{\text {mould, }}$ a premature cooling of the polymer melt inside the cavity was prevented. In this case, the magnitude of the effect (i.e. the slope of the line in main effects plot) of the real process was larger than the simulated one. On the other hand, an increase of melt temperature resulted in a reduction of the outer diameter. This happening was predicted by simulations too. As for $T_{\text {mould }}$, the effect of $T_{\text {melt }}$ was underestimated by the numerical model. This may have been caused by the fact that, starting from a higher temperature of the melt, the ring outer diameter was object to a larger amount of shrinkage at the end of the moulding process. The effect of the injection speed was non-linear, since the central level produced higher results than the low and high ones. This behaviour, which was also predicted by the simulations, could be due to larger residual stresses originated at high injection speed because of the more drastic cooling rate. The effect of the real process was once again underestimated by the numerical analysis results. The effect of the holding pressure was the one that was best predicted by simulations. The direct relation between OD and phold was caused by the fact that a higher holding pressure allowed more material inside the cavity and consequently resulted in a better cavity replication. The tendency towards compression of TPE might have helped such phenomenon. The numerical model accurately predicted such a trend: the deviations of experimental and numerical results of the three $p_{\text {hold }}$ levels ranged between $0.0 \mu \mathrm{m}$ and $2.6 \mu \mathrm{m}$. It is possible to conclude that $\mu \mathrm{IM}$ simulations were capable of accurately predicting the effects of the four process parameters: the slopes of the main effects plots for real and simulated results had the same sign in all the investigated ranges. Therefore, the numerical model was considered as validated with respect to the prediction of the effects of the investigated process parameters on the functional geometry OD.

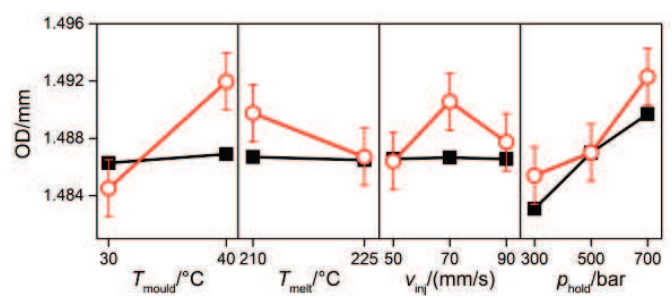

Fig. 5. Main effects plots for OD. The results of both measurements of real parts (in red) and of numerical simulations (black) are indicated. The errors bars indicate the expanded measurement uncertainty $U$.

\subsection{Virtual process optimization}

The calibrated and validated model was used to virtually optimize the process with respect to the OD target of $1.5 \mathrm{~mm}$. To do this, a further experimental 
campaign was carried out. Table 2 shows the selected conditions. A two-level full factorial experimental plane was designed and simulated. In particular, only phold, $T_{\text {mould }}$ and $T_{\text {melt }}$ were varied as they were the only significant factors for the simulations results of the previous experimental campaign, as also confirmed by ANOVA analysis. The levels of the parameters for the optimization plane were selected according to the previous trends (see Fig. 5) with the aim of increasing OD towards the target of $1.5 \mathrm{~mm}$. The level of injection speed was kept at $70 \mathrm{~mm} / \mathrm{s}$.

Table 2. Virtual optimization settings

\begin{tabular}{ll}
\hline Process parameter & Levels \\
\hline Holding pressure $p_{\text {hold }} / \mathrm{bar}$ & 900,1100 \\
Melt temperature $T_{\text {melt }}{ }^{\circ} \mathrm{C}$ & 180,195 \\
Mould temperature $T_{\text {mould }}{ }^{\circ} \mathrm{C}$ & 50,60 \\
\hline
\end{tabular}

Fig. 6 shows the results of the virtual optimization. As for the previous experimental campaign, a clear effect of the holding pressure is evident: increasing phold determined an increase of OD. Particularly, considering the target for OD of $1.5 \mathrm{~mm}$, selecting a holding pressure of 1100 bar was strongly suggested by the simulations results. As for the effect of mould temperature, its increase was important to achieve the desired dimensional output for the micro rings and therefore the setting of a $T_{\text {mould }}$ of $60^{\circ} \mathrm{C}$ was necessary to get closer to the specification target. The effect of $T_{\text {melt }}$ was less important, in particular when using high levels of $p$ hold and $T_{\text {mould. }}$.

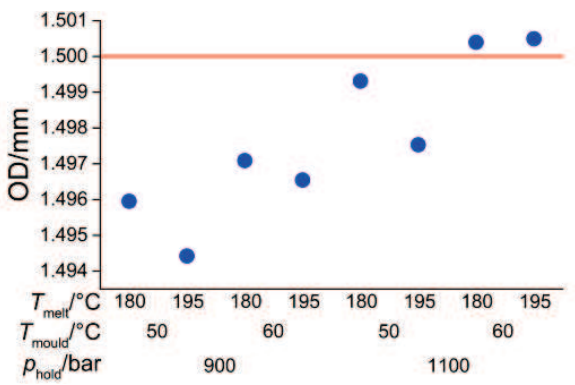

Fig. 6. Individual value plot for results of the virtual optimization plane. The red line represents the OD target.

\section{Conclusions}

The present work investigated the applicability of $\mu \mathrm{IM}$ simulations as tool for product/process optimization. A DoE campaign was carried out to evaluate the effects of $\mu \mathrm{IM}$ process on the dimensional accuracy of TPE micro rings. The outer diameter OD was selected as response for the analysis and term of comparison between experimental and numerical results. ASMI 2016 was used to mesh the model and run the analyses.

The numerical model was calibrated with respect to its dimension by fitting $O D$ to the experimental observations. This procedure allowed defining the best model that was then validated by comparing the effects of the process parameters on real experiments and numerical simulations. An average deviation of $1.6 \mu \mathrm{m}$ was observed between real part measurements and simulations results, demonstrating that a single digit micrometric accuracy can be achieved in $\mu \mathrm{IM}$ simulations by means of an appropriate model. Moreover, the effects of the four process parameters were correctly predicted. The model was then used to optimize the level of the investigated process parameters based on the results of the validation. Such an optimization allowed defining optimal values of holding pressure and moulding temperature with respect to the achievement of the target OD value.

Future studies will be dedicated to extend the presented approach by simultaneously considering multiple functional geometries.

\section{Acknowledgements}

This research work was undertaken in the context of MICROMAN project ("Process Fingerprint for Zerodefect Net-shape MICROMANufacturing", http://www.microman.mek.dtu.dk/). MICROMAN is a European Training Network supported by Horizon 2020 (Project ID: 674801).

\section{References}

[1] L. Alting et al., "Micro Engineering", CIRP Ann., 2003; 52: 635-657.

[2] J. Giboz et al., "Microinjection molding of thermoplastic polymers: a review", J. Micromech. Microeng., 2007; 17: R96-R109.

[3] G. Tosello et al., "Micro Injection Moulding High Accuracy Three-dimensional Simulation and Process Control", Proc. Polym. Process Eng. 11, 2011.

[4] G. Tosello et al., "Experimental validation of micro molding simulations using different process settings conditions", Antec 2009 Proc., 2009; 1787-1793.

[5] L. Wang et al., "Scale effect on filling stage in microinjection molding for thin slit cavities", Microsyst. Technol., 2012; 18: 2085-2091.

[6] A. Gava et al., "On the performance of a viscoelastic constitutive model for micro injection moulding simulations", Express Polym. Lett., 2012; 6: 417-426.

[7] C.S. Chen et al., "Rheological behavior of POM polymer melt flowing through micro-channels", Eur. Polym. J., 2008; 44: 1891-1898.

[8] M. Heinle et al., "Heat Transfer Coefficient in Injection Molding of Polymers", Int. Polym. Process., 2015; 30: 434-441.

[9] S.A. Khalilian et al., "The Application of Commercial Injection Molding Software to Micro-Component Design and Process Development", Proc. 8th Int. Conf. Micro Manuf. (ICOMM 2013), 2013; 50-56.

[10] D. M. Marhöfer et al., "Advancements on the simulation of the micro injection moulding process", Proc. 10th Int. Conf. Multi-material Micro Manuf. (4M 2013), 2013.

[11] F. Costa et al., "Best practice strategies for validation of micro moulding process simulation", Proc. of Ppe'09, 2009; 331-364.

[12] D. M. Marhöfer et al., "Gate Design in Injection Molding of Microfluidic Components Using Process Simulations", J. Micro Nano-Manufacturing, 2016; 4: 025001.

[13] ISO 15530-3: Geometrical product specifications (GPS) Coordinate measuring machines (CMM): Technique for determining the uncertainty of measurement, 2011. 